\title{
Developmental Impact OF Health-Related Beliefs in Women: A Cultural Analysis
}

\author{
Prof. Aradhana Shukla \\ Fellow (ICSSR), Dept. of Psychology, \\ Kumaun University, SSJ Campus, Almora \\ Email: aradhana.shukla5@gmail.com
}

\begin{abstract}
The aim of this study was to find out the impact of cultural variation, chronological age, and marital circumstances on healthrelated beliefs. It was contended that: (i) variation in culture would lay its impact on health-related beliefs, (ii) age-related variation would cause variation in health beliefs and (iii) women accompanying with their husbands and far from their husbands would show variation in health-related beliefs. 240 women of 25 60 years were taken in consideration and they were arranged according to the requirements of $2 \times 2 \times 2$ factorial design with 2 types of culture (Bhotia tribes and general Kumauni), 2 levels of age (2530 years and 55-60 years) and two 2 types of marital circumstances (wives accompanying with their husbands and wives far from their husbands) ie, 30 participants per all. Health belief scale (Dubey\&Tripathi, 2013) was taken into consideration. Data were analyzed by three-way ANOVA and it was noted that (i) Bhotias and general Kumaunies were highly discrepant in health-related beliefs, (ii) younger participant'sshowedless health beliefs than the older ones and, (iii) health beliefs were not so pounced compared to the participants accompanied by their husbands. All interactions were significant.
\end{abstract}

Findings were interpreted in terms of cultural variation, chronological age, and marital circumstances as affectors of healthrelated beliefs, at last, suggestions were made to promote good health beliefs in women.

Keywords: Culture, health beliefs, marital circumstances.
Reference to this paper should be made as follows:

Received: 25.04 .2020

Approved: 30.06.2020

Prof. Aradhana Shukla DEVELOPMENTAL IMPACT OF HEALTH-RELATED BELIEFS IN WOMEN: A CULTURAL ANALYSIS

RJPSSs 2020, Vol. XLVI, No. 1, pp. 01-14 Article No.01

Online available at:

http://rjpsss.anubooks.com/ https://doi.org/10.31995/ rjpsss.2020v46i01.01 
DeVelopmental Impact of Health-Related Beliefs in Women: A Cultural ANaLysis

Prof. Aradhana Shukla

\section{Introduction}

Health is important for both males and females. But it is in some way and in a different way essential for females because they usually play a pivotal role in domestic accountability, child-care and different loved ones' chores; Ladies have longer lives than males but they have got no longer a better quality of life. Seeing that of their biological and physiological makeup they may have bigger rates of acute illness, respiratory and digestive health problems, and nonfatal illnesses like, arthritis and headache, osteoporosis, thyroid issues, and Alzheimer's ailments are extra usual in females than males (National Care for Health, 2000; Ready Flaming and Adesso, 1992). Well, being behaviors comprise eating patterns, use of tobacco, alcohol and other mood-altering substances, and exercise, via difference within the family as good as through females themselves. Other behaviors that affect ladies' wellness incorporate, contraception, breastfeeding, and the usage of extraordinary forms of prescription (Moss, 2003).

It has been stated that the high rate of maternal mortality was reported in The Gambia is influenced by many factors, such as difficulties in accessing quality healthcare and facilities. In addition, socio-cultural practices in rural areas may limit resources.

\section{Health Beliefs}

Beliefs signify the understanding people have a couple of habits (Ajzen, 1971). Health beliefs are a persons' recommendations about health and health problems that a person holds and these beliefs play a tremendous function in shaping wellness practices. It is famous that the patient's own beliefs about their wellness and healing keep an eye on their wellness conduct to a fine extent than the health practitioner's

beliefs or solves the purpose of medical information (Roberts et. al, 1984). Wellbeing perception can also be developed by way of experiences, from seeing neighbors or household and expertise received via the media. Health beliefs appear in advance rather early in existence via the age of 11 or 12 years in most which children have rather steady well-being beliefs that resemble these of adults (Lau \&Klepper 1988). As a result, a belief system arises as a response to an environmental and social situation. All the know-how is arranged into beliefs procedure that may be as large as an entire cluster or as small as a cluster of attitude (Frizda, Manstead, and Bem, 2000).

The health beliefs are commonly explained in term of causal health beliefs, internal and external causal well-being beliefs, control wellbeing beliefs (confident and terrible control health beliefs), perspective towards health (optimistic and negative 
RJPSSs, Vol. XLVI No.1, June 2020 ISSN: (P)0048-7325 (e) 2454-7026 Impact Factor 7.821 (SJIF)

https://doi.org/10.31995/rjpsss.2020v46i01.01

angle towards wellness) and already it has defined that these are developed by means of personal expertise, from seeing goals, or household and expertise obtained through the media. Wellness beliefs are usually defined in term of :

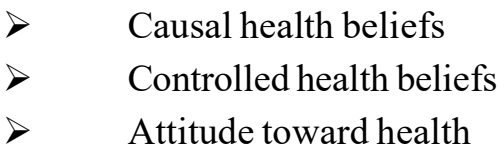

\section{Health Beliefs Model}

Health Beliefs, which define the unique perspective of individuals within a culture are an important part of understanding cultural competence for the health care provider, Health beliefs influence the perception of health care and the health care provider, as well as the decision to access and follow through with health care treatment, including medical evaluation and treatment.

This notion was once initially used by Rosenstok (1966) and was once modified by way of Becker and Maiman (1975). It predicts health-protecting behavior earlier than health problems and compliances with clinical regimens-as soon as sick. As a result, this model talks about both healthy as well as in poor health role conduct.

\section{Understand Susceptibility}

Every person has his/her own belief in the probability of experiences a situation that might adversely impact one's well being. There are broad versions of contributors in their belief of susceptibility to a disorder or situation.

\section{Perceive Seriouness}

It refers to the beliefs a person holds involving the result of a given disease or condition. These effects may also be considered from the point of view of the difficulties that a disorder would create.

\section{Barriers of Taking Action}

Barriers related to the personality sticks of a healing or preventive measure may be inconvenient, unpleasant, painful, or upsetting. These character sticks could lead an individual away from taking the wish action. If a man or woman beliefs that the advantage of taking action is effective. They can takes the action for remedy. Then again, if they believe that benefit of taking action is not strong, they do not take action for therapy.

\section{Cues to action}

Cues to action may be inside or outside. It will trigger a consideration of the endorse health action. An individual's notion of the stages of susceptibility and seriousness furnish the force to behave, and benefits provide the trail of action. However, it may require a cue in action for wish conduct to arise. 
The model has used gaint success to foretell the adoption of a few special health behaviors, including vaccinations, screening for cancer, and contraceptive habits (Harrison, Muller and Green, 1992; Herold, 1983; Janz\& Bicker, 1984). The health belief model (turned as HBM later on) has been utilized to a huge variety of well- being behaviors and subject populace(Conner \& Norman, 1996).

Three Medical institution uses, which includes medical professional visits for a form of rationale. The predominant difficulty with HBM is that's assuming rationality as the basis for a characters selections making and downplays the position of emotions it additionally tends to count on that beliefs are static and as soon as fashioned, really, constant designing right exams of the HBM and evaluating its results throughout studies. It also no longer an effortless assignment. These motives could incorporate specific influences, cultural explanations, socio monetary popularity, and previous experiences.

Walton, Akram, and Hossian (2014) studied determine specific health beliefs important to Muslim women as they relate to participation in medical, psychological, or social evaluation and treatment and to determine whether any of their beliefs, attitudes, or perceptions affect the female. Muslim patient's decision to access and follow through with medical evaluation and treatment was examined. Health beliefs also studied by Joshi and Shukla(2018) and Joshi(2018) from a cultural perspective.

Keeping these views into consideration this short was planned and it was aimed to find out the impact of cultural variation, chronological age, and marital circumstances on health-related beliefs. The objectives and hypotheses were as follows :

1. The first objective of the study was to find out the impact of cultural variation on health-related beliefs. It was hypothesized that variation in culture would cause a variation in the health-related beliefs of the participants.

2. The second objective of the investigation was to explore the relative efficacy of chronological age on health-related beliefs. It was contended that agerelated discrepancy would reveal a discrepancy in the scores of healthrelated beliefs of the participants.

3. The third objective of the study was to ascertain the impact of marital circumstances on health-related beliefs. It was assumed that variation in marital circumstances would lay its impact on health-related beliefs.

4. The fourth objective of the study to analyze the data in qualitative mode. It was thought that some new findings and notions will appear on the floor.

These objectives and hypotheses enabled the researcher to work on and 
achieve something that has not been appeared still yet.

\section{Method}

Tab le 1

Schematic presentation of experimental design

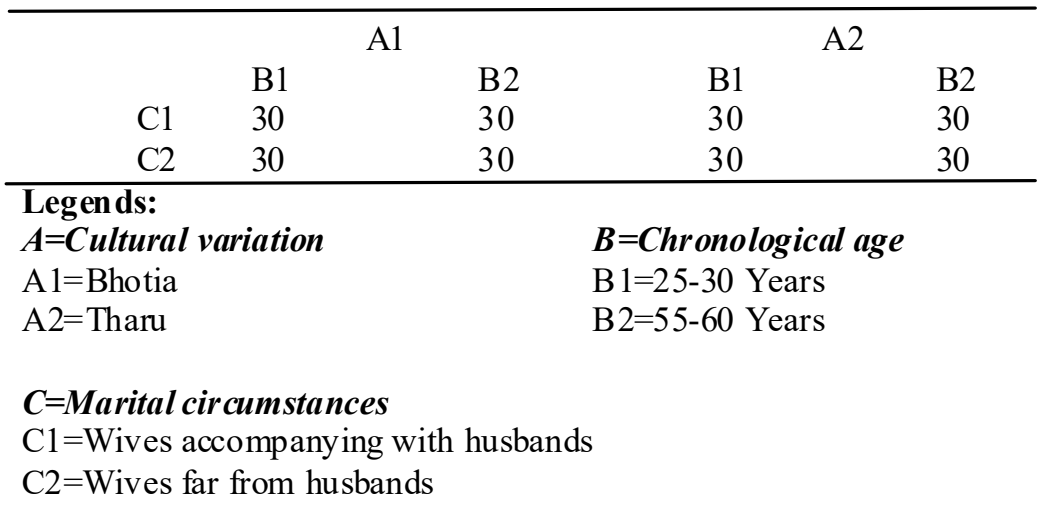

\section{Sample}

As this study was a part of a major project of ICSSR, New Delhi a sample of 240 women ranging between 25-60 years served as participants. They were arranged in accordance with the requirements of 3-way factorial design with 2 types of cultural variations (Bhotia tribe and general Kumauni),2levels of chronological age (25-30 years and 55-60 years) and 2 levels of marital circumstances (wives accompanying with husbands and wives far from husbands) ie 30 participants per cell. The schematic presentation of experimental design is as follows :

\section{Materials}

In this study, two types of measures were taken into consideration. They were termed as quantitative and qualitative measures. They are as follows :

\section{Quantitative measures}

This scale was developed by Dubey and Tripathi (2013). This scale has 49 items related to three aspects of health namely, causal health beliefs (12), control health beliefs (12), and attitude towards health (25). They deal with different health cognitions of the women. The split-half reliability is +.73 .

\section{Qualitative measures}

\section{Health Belief Interview Schedule}

Contructed by Dubey and Tripathi (2013) this interview schedule is comprised of four aspects of health ie; casual health beliefs. control health beliefs, attitude towards health, and harmful health beliefs. In this regard following basic questions 
were asked :

1. What are the causes you attribute to your illness?

2. Whenever you become ill, which kind of thought comes in your mind?

3. Whenever you become ill, how do you do to come out of it?

4. Narrate any such incidence, when you want to do positive health behavior but due to any pressure you have done is cantraybehaviour.

\section{Procedure}

At first the investigator contacted the target place from where the data heal to be taken place. Then the researcher contacted tribal women at Pithoragarh and Dharchula and General Kumauni women at AlmoraUttarakhand from where the data were collected. Researcher took the help of some pradhans to collect the data of tribal women. Data collection was made individual/in-group as per the convenience of the participants and their availability and best efforts were made to avoid external distractions.

\section{Results}

Obtained data were analyzed in two sections. In section one impact of cultural variation, chronological age and marital circumstances on health-related beliefs and section two analyzed the data qualitatively. The detailed description is as follows :

Section-One- Impact of cultural variation, chronological age, and marital circumstances on health-related beliefs

Obtained data were analyzed by 3-way ANOVA and interpreted in terms of cultural variation. chronological age and marital circumstances on health-related beliefs findings are given in table 2.

\section{Table 2}

Summary table of analysis of variance showing the impact of cultural variation, chronological age and

\begin{tabular}{lcccc}
\multicolumn{5}{c}{ marital circumstances on the health -related belief } \\
\hline $\begin{array}{l}\text { Sources of } \\
\text { Variation }\end{array}$ & $\boldsymbol{S s}$ & $\boldsymbol{D} \boldsymbol{f}$ & $\boldsymbol{M S}$ & $\boldsymbol{F}$ \\
\hline $\boldsymbol{A}$ & 5.13 & 1 & 5.13 & 5.19 \\
$\boldsymbol{B}$ & 5.10 & 1 & 5.10 & 5.16 \\
$\boldsymbol{C}$ & .72 & 1 & .72 & .73 \\
$\boldsymbol{A B}$ & 8.72 & 1 & 8.72 & 8.81 \\
$\boldsymbol{A C}$ & 6.54 & 1 & 6.64 & 6.61 \\
$\boldsymbol{B C}$ & 4.61 & 1 & 4.61 & 4.66 \\
$\boldsymbol{A B C}$ & 6.52 & 1 & 6.52 & 6.59 \\
Error within & 234.32 & 232 & 1.01 & \\
\hline & & 239 & &
\end{tabular}


A close perusal of the table indicates that the main effect of cultural variation was significant $(\mathrm{F}, 1,239=5.19 \mathrm{P}<.01)$ and it showed that Bhotia women were less careful about health beliefs $(X=24.65)$ as compared to general Kumauni women $(X=197.23)$. The next main effect of chronological was also significant $(\mathrm{F}, 1.239=5.16 \mathrm{P}<.01)$, and it was noted that young participants have higher health beliefs $(X=198.84)$ than the older ones $(X=213.35)$. The last main effect of marital circumstances was insignificant $(\mathrm{F} 1,239=0.73 \mathrm{P}>.05)$. It was noted that women of accompanying husbands $(X=202.97)$ and far from their husbands $(X=208.91)$ were slightly different in relation to their scores on health belief scores.

The two-way interaction of cultural variation and chronological age was significant $(\mathrm{F} 1,239=881 \mathrm{P}<.01)$ and it appears in figure 1 .

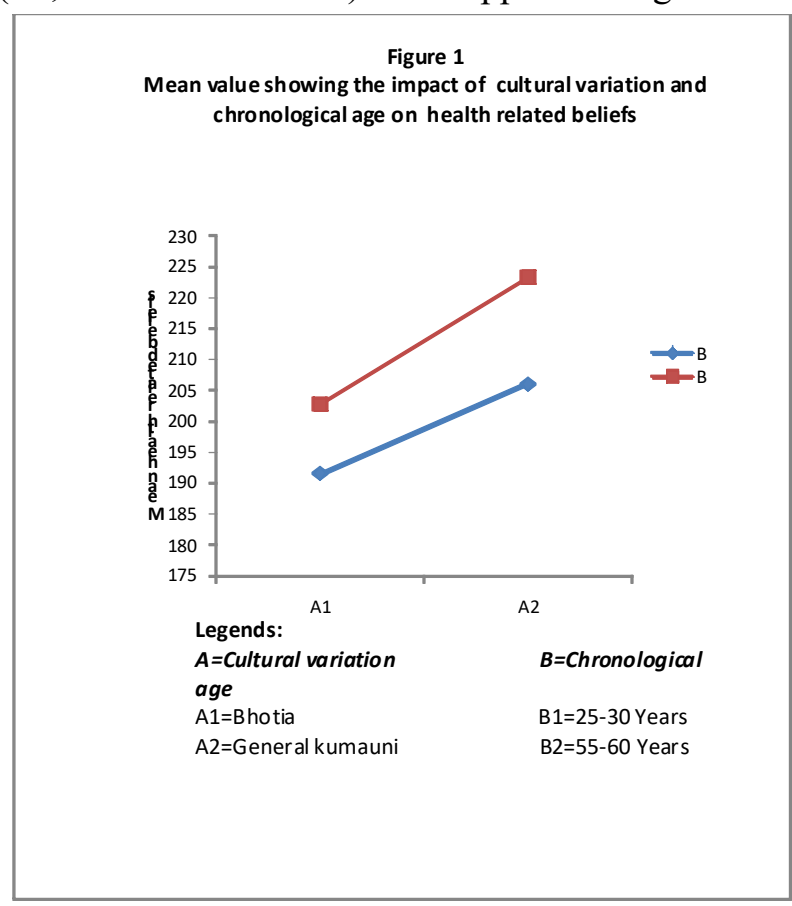

Figure1 


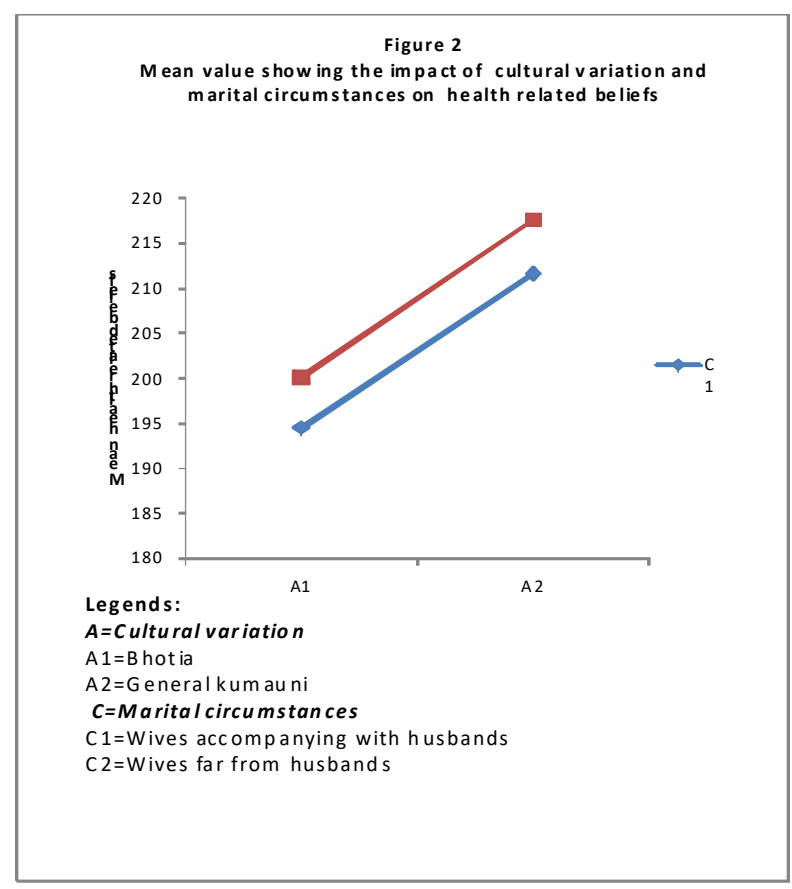

Figure2

A close Perusal of the figure reveals that the magnitude of health-related belief was relatively high in the general Kumauni group. Similarly, 55-60 years old participants revealed more health-related beliefs then the younger ones. The cultural variation and marital circumstance interaction were also significant $(\mathrm{F} 1,239=6.61$ $\mathrm{P}<.01)$ and it is depicted in figure 2.

Figure reveals that discrepancy related to health belief was more pronounced in the women accompanying with their husbands. The magnitude of discrepancy was more or less the same in both cultures.

The chronological age and marital circumstances interaction were also significant $(\mathrm{F} 1,239=4.66 \mathrm{P}<.01)$ and it appears in figure 3 . 


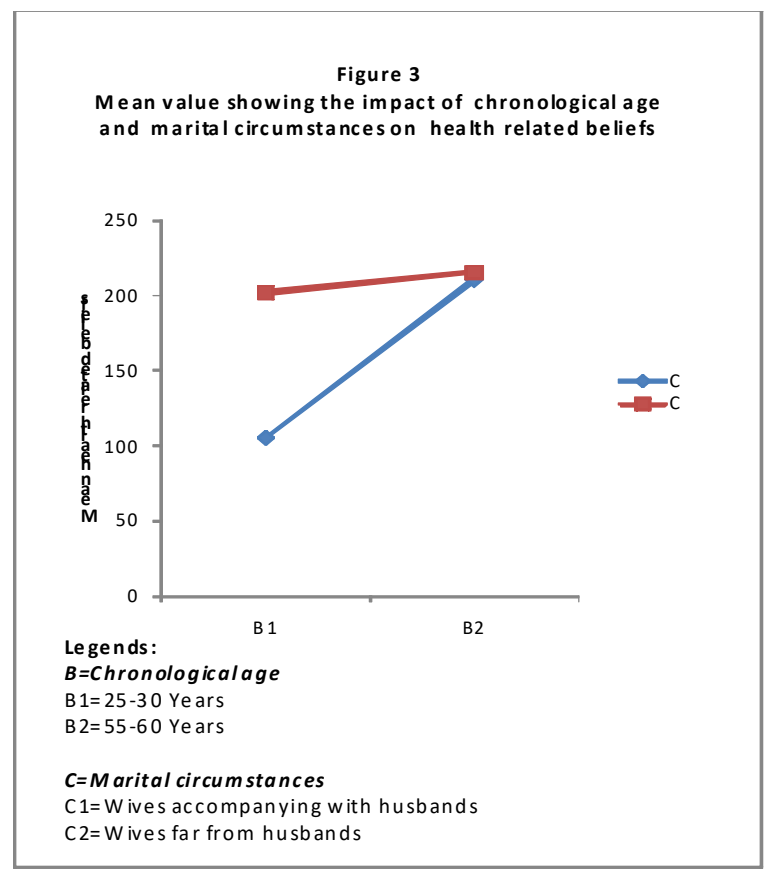

Figure3

Figure reveals that age-related discrepancy was more pronounced in the women accompanying martitalwith their husband. Also, it was noticed that discrepancy related to martial circumstances was more pronounced in the women accompanying with their husband.

The three-way interaction of cultural, variation, chronological age, and marital circumstances was also significant $(\mathrm{F} 1,239,6.59 \mathrm{P}<.01)$, and it appears in figure 4 .

A close perusal of the figure reveals that all variables laid their impact on health-related behavior. 


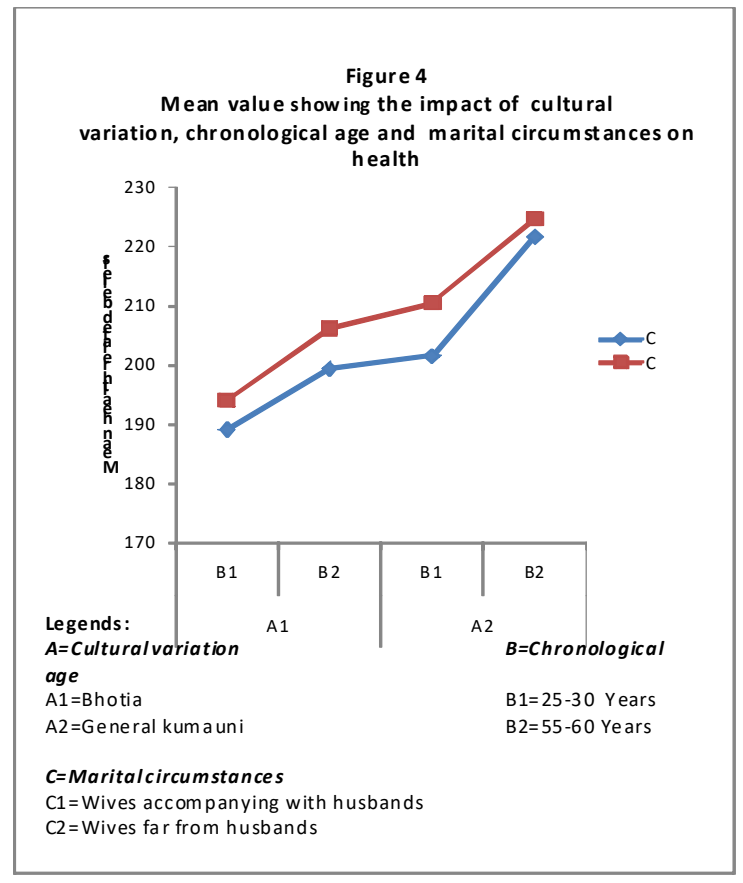

Figure4

Qualitative analysis of data: This section reveals the explanations of the responses of qualitative data.

(i) Casual health beliefs: The outcome confirmed a quantity and variety of causes by the way the people use. The factors observes during evaluations were: carelessness, laziness, irregular hobbies, lack of physical activities and precautions, less well being, lack of emotional aid, poverty, eating stale food, domestic clashes, pollution, Chua-chroot black eyes (Nazar Lagna) and black magic, etc.

(ii) Control health beliefs: The obtained responses had been complying with precautions, domestic treatment for minor issues, consulting with certified medical professionals, cleaning residence clothes and body, jhadphoonk, tona, and total, nazarutarana and so on.

(iii) Attitude towards health: The theme emerged from the responses of the respondents like they want to get early, proper medication intake, prayer to God may also help fear of dying soon feeling of loneliness wish of dying before husband's death appeared as the main issues.

(iv) Harmful health beliefs: In principle, respondents hold that they could not do anything without the will of their husbands and other family members. They personal 
more family stress in health associated habits as many of them want to take medicines, do not go to normal healers or jhadphoonk. However, they know that someone of kind facts like rituals, traditions, or culture is tough to alter.

Some ladies told that they did not worry about diseases. They were satisfied in the sense that they die in the presence of their husbands. Some widows showed a tendency to avoid the worship of God because they lost their faith over Him after the death of their husbands. Some showed their deep faith to God and the told that he will cure-all.

In this way, data were analyzed qualitatively and quantitatively both.

\section{Discussion}

Obtained findings were analyzed by analysis of variance and interpreted in terms of cultural variation, chronological age, and marital circumstances as predictors of health-related beliefs. Prior to the conception of the study, some hypotheses were formulated and the findings will be discussed accordingly.

Variation in culture would cause variation in the health-related belief of women

Our first and foremost hypothesis was related to the impact of cultural variation on women's health belief. It was found that cultural variation laid its' significant impact on health-related beliefs. Participants of the general Kumauni population were found more careful about their health as compared to the tribal population. It showed that living in open culture and being educated it is very obvious to take care of ones' own health. The participantsofgeneral Kumauni were taken from Pithoragarh and Almora city, Uttarakhand which is open places and there are ample avaneuesfor development and cultivating oneself. One the contrary, data of tribals were taken from their root places where they lack the opportunities to be developed. In addition, it was also noticed that the tribal women were surrounded by their own societies and chance the hope of development was very nominal. Once a person sees the society and observes the new innovations prevailed there, he/she tries to cope with them. Contrary to this if the society does not have many amenities and scope naturally no new cognition will appear in the mind. During data collection it was found that tribal were less oriented towards the development and maintenance of their health they told, Saying this they did not lose a sense of hopelessness or despair but they were normal and it appeared in the qualitative analysis also. So it is surely fair to say that culture plays an important role while shaping a person.

\section{(ii) Variation in chronological age would cause variation in health-related} beliefs 
Our second notion was related with the age-related development in healthrelated beliefs, It was noted that young participants were careful about their health beliefs as compared with older ones. It was noted, while collecting the data that older women (although not so old) were careless about their health. They opined." and so on.

They believed in their past diet, nourishments, and many things more. So far as the matter of young participants was concerned they were interested to maintain their health. They told us that they were taking a balanced diet, nutrients, and yogic exercises to maintain their health. Moreover, they tended their interest in the health care of their families and their own self also. As they were young and more educated so they knew all advancements and progression following which they can get a good health. Findings in sum support our hypothesis and state the fact that younger participants were more prone to health and its beliefs.

(iii) Variation in marital circumstances would lay its impact on health beliefs

Our third concern was related to the relative efficacy of marital circumstances or health beliefs. It was noted that health belief was more pronounced in the women living with their husbands while participants far from their husbands showed a sense of health negligence.

During data collection, it was noted that the women, far from their husbands had to perform the role of all sorts because they had to take the care of all. Women accompanied by their husbands were happy and satisfied (almost) and they got the time to pay attention to their own health. Also, it was noted that they were shared the household chores and other responsibilities by their husbands, So, they cared for themselves.

Findings, in general, support our hypothesis that variation in marital circumstances would its impact on health beliefs.

\section{(V) Qualitative analysis of the data}

It was the last objective of the study in which qualitative data were taken based on four questions relating to (i) casual health belief (ii) control health beliefs (iii) attitude towards health and (iv) harmful health beliefs. Interpretation of there aspects was presented in detail but in nutshell, participants shared their views pertaining to the question. As it was noted that each participant was too curious and prompt to share the views, they contributed the experienced about the attributions of their illness, perception, or experience to come out of it, attitude about their own health, and narrating their past experiences regarding their harmful health. 
On the whole, it can be said that the magnitude and variation in health beliefs are caused by culture variation, chronological age, and marital circumstances. Better attempts are required to promote health belief and it will create a positive wave in the society.

\section{References}

1 Ajzen, I. (1971). Attitudinal vs. normative messages: An investigation of the differential effects of persuasive communications on behavior. Sociometry, 34, 263-280.

2 Becker, M.H., \&Maiman, L.A. (1975). Socio-behavioral determinants of compliance with health and medical care recommendation. Medical Care, 13, 10-24.

3 Dubey, A. \&Tripathi, K.M. (2013).Health belief scale, Unpublished Scale, Department of Psychology, DDU Gorakhpur University Gorakhpur.

4 Harrison, J.A., Muller, P.O. \& Green, L. (1992). A meta-analysis of studies of the health belief model with adults. Health Education Research, 7, 107116.

5 Herold, E.S. (1983). The Health Belief Model: Can it help us to understand contraceptive use amongst adolescents? Journal of School Health, 53, 19-21.

6 Janz, N.K., and Becker, M.H. (1984). The health belief model: a decade later. Health Education Quarterly, 11, 1-47.

7 Joshi, B. \&Shukla, A. (2018).Health beliefs of Kumauni women as affected by their marital status and age.Recent Educational and Psychological Research, 7, 2, 17-28.

8 Joshi.B.(2018). Effect of marital status, age, and culture on life satisfaction, temperament and health beliefs, Unpublished Doctoral Thesis, Department of Psychology, Kumaun University, Nainital.

9 Lau, R.R. \&Klepper, S. (1988). The development of illness orientations in children aged of 6 through 12, Journal of Health and Social Behaviour, 29, 149-168.

10 Moss, N. E. (2003). Gender equity and socioeconomic inequality: A framework for the patterning of women's health. Social and Economic Patterning of Health among Women / Les facteurssociaux et économiques de la santé des femmes, Arber S. and Khlat M., (eds.), Paris, CICRED, pp. 29-56. 
11 National Centre for Health Statistics (2000). Health, United States, With adolescent health chartbook. Hyattsville, Maryland.

12 Ready, D.M., Flaming, R., \&Adesso, V.J. (1992). Gender and Health. In S. (Eds.) International Review of Health Psychology (Vol.1, pp.3-32) New York: Wiley.

13 Robert, N. Smith E., Bennet, S. Cape, J., Norton R., \& Kilburn, P. (1984). Health Beliefs and Rehabilitation after lumbar disc surgery Journal of Psychological Research, 28, 139-144.

14 Rosenstock, I.M. (1966) Why people use health services. Millbank Memorial Fund Quarterly, 44, 94.

15 Walton, L.M., Akaram, RDMS, BS, F., and Hossain, BBA, F. (2014). Health belief in Muslim women and implications for health care providers: Exploratory study on the health beliefs of Muslim women, Online Journal of Health Ethics, 10(2). 